\title{
STUDENTS' PERCEPTIONS OF CLINICAL PLACEMENTS IN AUSTRALIAN PRISON HEALTH SERVICES: A MIXED METHODS STUDY
}

Associate Professor Thea F. van de Mortel, PhD, MHlthSc, Bsc(Hons), DipNurs

Deputy Head of School (Learning \& Teaching)

*School of Nursing and Midwifery, Griffith University,

Parklands Drive, Southport, QLD, Australia, 4222

Ph: +61 75552 7855; Fax: +61 75552 8526; email: t.vandemortel@griffith.edu.au

Dr Judith Needham, EdD MN(Management) BN RN RM

Professional Practice Director,*

Ms Kate Barnewall, MAdvPrac GradCertHlthProfEd BN RN RM

Professional Practice Coordinator,*

Ms Ashleigh Djachenko, BN, GCertCPrimaryHCare, GDipHealthRes, RN

Nurse Educator, West Moreton Hospital Health Service - Prison Health Service

Locked Bag 500, Archerfield, Qld 4108

email: Ashleigh.Djachenko@health.qld.gov.au

Ms Jennifer Patrick, MAdvPrac (InfPrevent\&Cont) GradCertCritCare(ICU) GradCertClinEd RN RM

Research Assistant,*

Acknowledgements

We are grateful for the Queensland Clinical Education \& Training Council grant that funded this project. 


\begin{abstract}
Increasing demands for clinical placements have forced tertiary institutions to look for alternative placements for third year nursing students. While Prison Health Services provide an opportunity for nursing students to engage in care of offender populations with significant chronic illnesses, there has been little evaluation of such placements.
\end{abstract}

Third year undergraduate nurses (18/46) participated in a mixed methods study to provide evidence-based research on students’ perceptions of clinical placements in Prison Health Services. Quantitative and qualitative data were collected via an anonymous survey and individual interview.

Whilst the majority of students valued the opportunity to increase their knowledge and clinical skills and felt supported by preceptors, challenges included being psychologically illprepared for the physical and emotional aspects of placement, and witnessing poor attitudes and behaviours of staff, which impacted on the quality of their experience.

Recommendations include changes to orientation programs and introduction of simulation to help students feel better prepared and supported during placements in prison settings. Refining the selection process for placements in this setting will also help to ensure student suitability for clinical placement in Prison Health Services.

Keywords: nursing students, prison health services, clinical placement, survey 
Highlights

- Eighty-nine percent of students who attended a prison placement rated it as effective

- Students wanted a detailed orientation and psychological preparation for dealing with offenders

- Preceptors needed training on providing constructive feedback and managing group dynamics

\section{INTRODUCTION}

Griffith University has participated in a new placement initiative with four metropolitan Prison Health Services since March 2014, and is the only tertiary provider placing nursing students in these facilities in our region. Given the very limited information in the literature on nursing students' experiences of these placements it was imperative to determine whether this new setting was providing quality clinical placements that met course aims and student needs. The study aim was to work collaboratively with Prison Health Services to investigate the student experience of placements.

Increasing demand for clinical placements required that innovative alternative placements for third year nursing students be sourced that provided opportunities to develop advanced decision-making skills to work with individuals and populations. Students needed to develop their nursing practice and explore concepts in relation to health promotion, primary health care, community development, primary care, health education and literacy, and cultural safety. To meet these needs, new placements were sought in non-traditional placement areas, including Prison Health Services. 
Prisoners often come from disadvantaged backgrounds and have significant, complex and often chronic health conditions (Australian Institute of Health and Welfare (AIHW), 2015). Recent national data obtained from Australian prisons confirmed that prisoners have higher levels of chronic disease, mental illness, substance abuse, disability and communicable disease than the general population, and indigenous Australians have incarceration rates 13 times higher than the general population (AIHW, 2015; Australian Bureau of Statistics, 2015).

Various socioeconomic factors are linked to poor health in offender populations including homelessness, previous incarceration, parental incarceration, poor education, cultural background and unemployment. As prison staff and visitors pass between the prison and the community, and prisoners may act as reservoirs of infection upon their release, prison health can also influence public health (Enggist, Moller, Galea, \& Uderson, 2014).

In the correctional setting the primary healthcare providers are nurses (Almost et al., 2013; AIHW, 2015; Durcan, 2006), and the secure, regulated, and punitive environment can be challenging when providing care for prisoners with complex health needs who may also be manipulative and/or aggressive. Prison health nurses require specialised knowledge, and excellent assessment and clinical decision-making skills to make a difference to the health and lives of their patients. They must also have knowledge of prison management procedures to ensure they work safely in this setting. In some countries, for example the United Kingdom, extensive work has been carried out to develop and evaluate educational programs for prison nurses to support them to provide quality care for offenders [see for example, Bennet, Perry, Lapworth, Davies and Preece (2010)].

Given that drug and alcohol abuse, and mental and physical illness increase the chance of recidivism (Thomas, Spittal, Taxman, \& Kinner, 2015; Warrilow, 2012), careful assessment, 
screening and vaccination, development of compliance and self-care behaviours, provision of care, management of mental illness, discharge planning, and preparation of offenders to improve healthcare access following release are ways in which nurses can impact on prisoner and community health and wellbeing (Enggist et al., 2014).

The complex health conditions and backgrounds of offender populations may provide a rich source of learning for nursing students on clinical placement, who may gain insights into issues that marginalised groups encounter (Filek et al., 2013).

\section{$\underline{\text { BACKGROUND }}$}

The health profile of the offender population offers an opportunity for nursing students to work with indigenous patients and those with mental illness, and develop their knowledge and skills in health promotion, population health, primary care, and advanced clinical decision-making.

There are various reports of student nurses completing clinical placements in correctional settings. For example, according to Felton, Parsons and Satterfield (1987) nursing participation in the correctional setting in the USA dates from the civil rights and antiwar movements in the 1960's. Subsequently, undergraduate student nurse placements have been reported in the Los Lunas Prison Farm in New Mexico (Kuaffman, Holbrook, Collier, Farabaugh, Jackson \& Johnston, 1979), South Carolina Department of Corrections (Felton et al., 1987), Rikers Island jail in New York (Georges, 1986; Tewa, 2014), Florida (Chappel \& Chase, 1986), Canada (Cohen \& Gregory, 2009), the United Kingdom (Faculty of Health Social Care \& Education, 2015; Norman, 1999), the Philippines (Juanitez, 2015), and in both private and public prisons in Australia (Forensicare, 2015; Justice Health and Forensic Mental Health Network, 2015; Martin \& Happell, 2001). 
While Prison Health Services are not traditional sources of clinical placements, Stewart (2007) suggests they could be beneficial to both students and staff. Some reported benefits include opportunities to develop skills in inter-professional teamwork, interpersonal relationships, patient advocacy, health assessment, health promotion and education and enhance practical skills (Georges, 1986; Tewa, 2014). Chapell and Chase (1986) agree such placements can enhance clinical skills particularly in health maintenance and illness prevention, while Cohen and Gregory (2009) suggest prison placements offer students opportunities to apply their knowledge and skills, while seeing health as rooted in social structures, enabling learning in relation to social justice, equity, and the social determinants of health. Similarly, Juanitez (2015) also noted increased awareness of the social determinants of health amongst students undergoing placements in prison health, and Werlin and O’Brien (1984) who surveyed Registered Nurses upgrading to a degree who were placed in the correctional setting, found that these students developed more positive attitudes towards prisoners.

Several studies have examined the benefits of placing students in prison mental health services specifically. Peternelj-Taylor and Johnson (1996) felt that placement of undergraduate nursing students in prison mental health services was useful to hone mental health nursing skills, and Martin and Heppell (2001), who evaluated student nurse placements at the Victorian Institute of Forensic Mental Health, found students’ understanding of mental health nursing increased and their attitudes towards mental health nursing became more positive.

However, the majority of the aforementioned studies did not formally evaluate the setting as a placement environment, or relied on course teachers views of the outcomes, and in the rare instances where undergraduate nursing students were asked about their experiences the sample size was very small and the data from nursing students were not identifiable from that 
of other health care students, or the study focused on one aspect of nursing experience such as mental health (Kauffman et al., 1979; Martin \& Heppell, 2001). Thus the aim of this study was to investigate student experiences of placements in the Prison Health setting. The specific research questions were:

1. What were students' perceptions of the Prison Health Services placement?

2. What were students' perceptions of their preceptors in this setting?

3. What could be done to improve the placement experience in this setting?

\section{RESEARCH DESIGN}

\section{Design and participants}

A mixed methods approach, including collection of quantitative and qualitative survey data and qualitative interview data from students placed with Prison Health Services, was utilised. All third year undergraduate nurses $(n=46)$ who attended placements in four metropolitan prisons in semester 2, 2015, were invited to participate.

\section{$\underline{\text { Setting }}$}

The setting included four maximum security, metropolitan prisons (see demographics in Table 1). Facilities 2 and 4 typically accept two students per placement, while the remainder take one. The facilities were staffed by primarily by Registered Nurses with the assistance of a small number of Enrolled Nurses; students were supervised by Registered Nurse preceptors. 
Table 1. Setting demographics.

\begin{tabular}{|l|l|l|l|l|}
\hline Facility & Prisoner type & No. prisoners & $\begin{array}{l}\text { Nursing staff } \\
\text { (FTE) }\end{array}$ & No. students \\
\hline 1 & Women & 350 & 20 & 11 \\
\hline 2 & Youth & 110 & 10 & 15 \\
\hline 3 & Men & 700 & 19 & 9 \\
\hline 4 & Men & 600 & 22 & 11 \\
\hline
\end{tabular}

\section{Ethics approval}

Ethics approval was obtained from the West Moreton Hospital and Health Service (HREC/15/QMWS/38) and Griffith University (GU Ref No: NRS/47/15/HREC) Human Research Ethics Committees.

\section{$\underline{\text { Recruitment }}$}

Students who had completed a prison placement were invited to participate via email in an anonymous survey of their experience. Completion of the survey was considered consent. Two reminder emails were sent to increase the response rate. Students were recruited for interviews via an email invitation from the researchers that included an information sheet and a consent form.

\section{Survey instrument and interview questions}

Individual 20 minute interviews were conducted by phone, using open-ended interview questions that elicited information about students' perceptions of the overall experience 
including the main objectives for students placed in this setting, how they engaged with clinical learning opportunities, their perceptions of the barriers and enablers of student learning in this setting, how well supported they felt, and what could be done to improve the experience. The survey contained 47 items including:

$\diamond$ Identification of the facility attended (1), and how many preceptors the students worked with (1).

$\diamond$ Global rankings of students’ overall perceptions of:

- the facility (1) and their preceptor/s (1) using 5-point Likert scales that ranged from unacceptable, poor, satisfactory, good, to outstanding.

$\diamond$ Students' perceptions of the facility and staff in general (on a 5-point Likert scale that ranged from strongly disagree to strongly agree) including:

- how the placement met the course clinical learning objectives (9),

- what qualities were displayed by facility staff (5),

- what learning experiences were provided (4), and

- what methods staff used to create a supportive learning environment (4).

$\diamond$ Students' perceptions of their preceptor/s, (using 5-point Likert scales ranging from strongly disagree to strongly agree) including:

- The preceptor's qualities (7), and

- The preceptor/s' specific actions or behaviours (8).

$\diamond$ Open response questions on what aspects of the facility they valued most (1), what aspects were most challenging (1) and suggested areas of improvement for the facility.

$\diamond$ Open response questions on their preceptor's strengths (1) and suggested areas of 
improvement (1).

$\diamond$ Further comments on their experience of the facility (1) and their preceptor (1).

\section{$\underline{\text { Data analysis }}$}

Descriptive statistics were calculated for quantitative data (mean and standard deviation).

Cronbach's alpha was calculated for scales. Thematic analysis was used to elicit themes from the qualitative data, using the steps described by Braun and Clarke (2009). Three researchers independently identified themes, and final themes were agreed upon by the team.

\section{RESULTS}

Eighteen of 46 students (39.1\%) completed the quantitative component of the survey. Qualitative data were obtained from 16 of 46 students (34.8\%): 14 via open-ended survey questions, one via an email response and one via interview. Seven, five, two and four students attended facilities $1,2,3$, and 4 respectively. Cronbach's alpha for the scales ranged from 0.86 to 0.99 .

\section{The Prison Health Services experience}

On the global rating of the clinical placement experience, $88.9 \%$ of students $(n=16)$ perceived that the placement was good to outstanding in terms of its effectiveness as a placement area (Fig 1). 


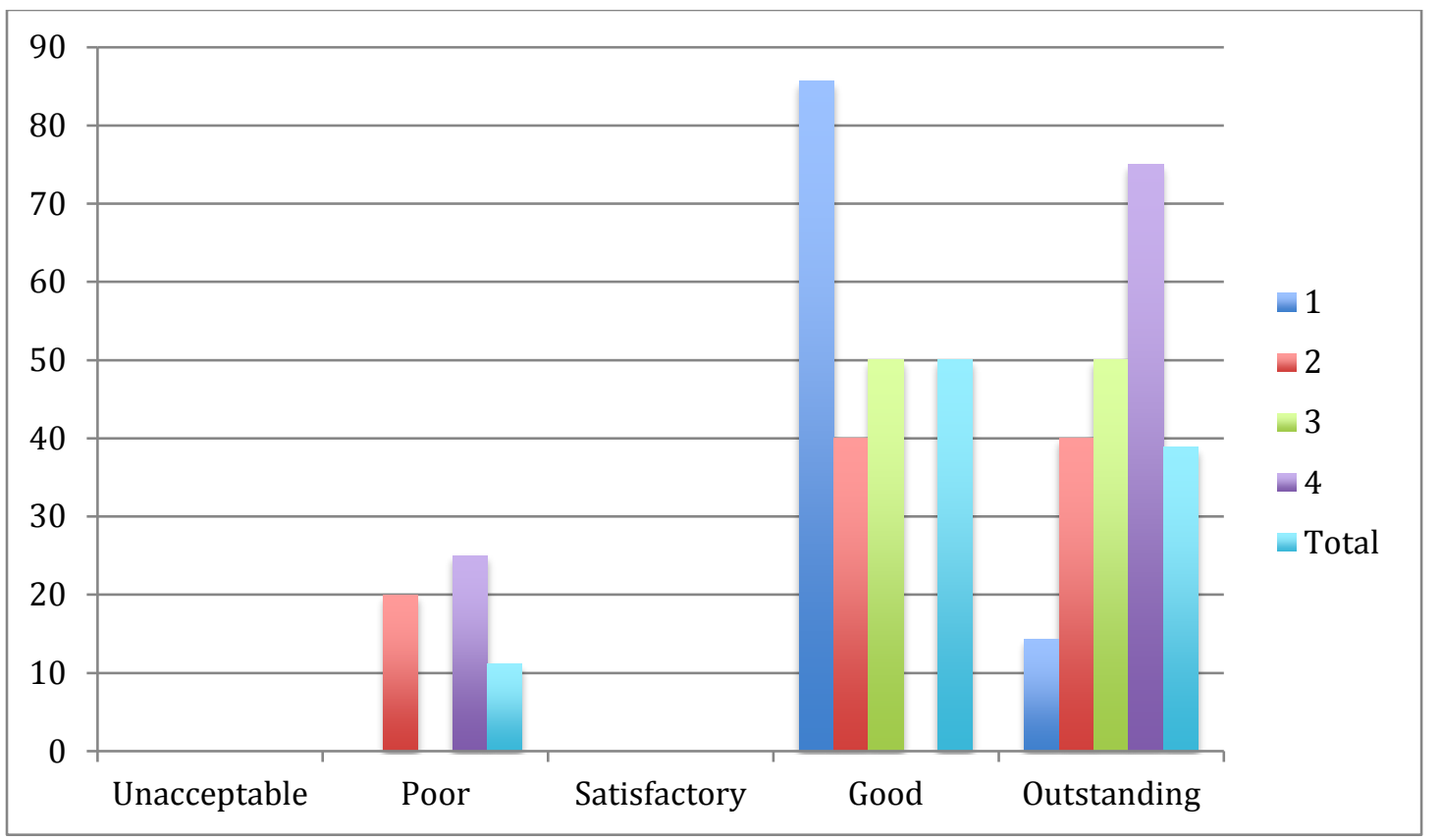

Figure 1. Students' overall perceptions of their experience in Prison Health Service facilities $1-4(\%)$.

Fourteen to 18 of 18 students agreed or strongly agreed that the health care facility was appropriate to meet the outlined objectives of the placement. Scores on the items ranged from 3.89-4.50 (mean $4.31 \pm 0.87$ ) (Table 2). Most students agreed that the learning experiences provided by the facility included critical thinking, client interaction, health assessment and hands-on experience (Table 3). Students were generally positive about the methods used by the non-preceptor staff in the health care facility to create a supportive learning environment (Table 4). 
Table 2. Student's responses to the item, 'The health care facility was appropriate for the set clinical objectives'.

\begin{tabular}{llll}
\hline & & & \\
Item & Disagree / & Agree / & \\
& Strongly & Strongly & Mean \\
& Disagree & Agree (n) & \\
& (n) & & \\
\hline
\end{tabular}

Observe the role/s of the correctional health centre nurse and discuss observations with $5.56 \%(1) \quad 94.44 \%(17)$ 4.50 preceptors $( \pm 0.79)$

Undertake under supervision provision of care to clients as they attend correctional health $5.56 \%(1) \quad 88.89 \%(16)$ services

Undertake a patient history under supervision

0

$100 \%(18)$

Engage in health promotion activities as appropriate

$16.67 \%(3) \quad 77.78 \%(14)$

4.06

Identify the major health issues in the correctional centre population and consider how they compare with those in the general population

$11.76 \%(2) \quad 88.23 \%(15)$

Discuss the concepts of 'duty of care' and 'equivalence of care' and how they relate to the provision of health services in correctional $5.56 \%(1) \quad 88.89 \%(16)$ centres

Identify the treatment options for clients with drug or alcohol dependence and compare these with options available to the general population

$11.11(2) \quad 88.89 \%(16)$ 
Explore the concept of 'harm minimisation' and identify the ethical issues and barriers to applying these principles in a correctional centre

$11.11(2) \quad 88.89 \%(16)$

4.22

$( \pm 1.12)$

$16.67 \%(3) \quad 77.78 \%(14)$

3.89

$( \pm 1.32)$

Mean ( \pm S.D)

Table 3. Students' perceptions of the learning experiences provided in Prison Health Services facilities.

\begin{tabular}{llll}
\hline Item & $\begin{array}{l}\text { Disagree / Strongly } \\
\text { Disagree (n) }\end{array}$ & $\begin{array}{l}\text { Agree / Strongly } \\
\text { Agree (n) }\end{array}$ & Mean \\
\hline Critical thinking & $5.56 \%(1)$ & $88.89 \%(16)$ & $4.56( \pm 0.86)$ \\
Client interaction & $11.1 \%(2)$ & $88.89 \%(16)$ & $4.39( \pm 1.14)$ \\
Health assessment & 0 & $94.44 \%(17)$ & $4.61( \pm 0.61)$ \\
Hands-on experiences & $5.56 \%(1)$ & $94.44 \%(17)$ & $4.56( \pm 0.98)$ \\
& & & $4.53( \pm 0.84)$ \\
\hline
\end{tabular}

Table 4. Students' perceptions of the methods used by staff to create a supportive learning 
environment.

\begin{tabular}{llll}
\hline Item & $\begin{array}{l}\text { Disagree/ } \\
\text { Strongly } \\
\text { Disagree (n) }\end{array}$ & $\begin{array}{l}\text { Agree / Strongly } \\
\text { Agree (n) }\end{array}$ & Mean \\
\hline $\begin{array}{l}\text { Including student in handover } \\
\text { Assigning student to competent } \\
\text { nurses to work with }\end{array}$ & 0 & $88.89 \%(1)$ & $4.33( \pm 0.84)$ \\
$\begin{array}{l}\text { Including student in patient } \\
\text { consultations }\end{array}$ & 0 & $94.44 \%(17)$ & $4.44( \pm 0.62)$ \\
& & $94.44 \%(17)$ & $4.44( \pm 0.62)$ \\
\hline Mean ( \pm S.D.) & & & \\
\hline
\end{tabular}

Most students viewed their placement positively, feeling welcome and well supported. When asked what they most valued about their prison health placement, the themes included Increasing Clinical Skills, Support and Relationships, the Qualities of Staff, and Something Different. Within the theme of Increasing Clinical Skills, students valued being 'allowed to do everything within my scope of practice (S10)' getting a wide range of experiences, and 'being able to autonomously perform tasks (S5).' For example, 'being allowed to do the reception interview and paperwork on my own - under supervision...enabled me to have interesting client interactions...really think about their needs...and advocate for them (S7).

Students also valued honing particular skills, for example, 'the health assessments on reception were very helpful in building up my assessment skills (S4), 'the opportunity to learn/improve on medications as it's a big part of the job (S7)', and 'the therapeutic relationships I formed with the offenders (S4)'. 
Students valued 'feeling part of the team (S11)', '[being accepted] as if I was a staff member (S17)', and 'the different learning environment (S9)'. Students valued staff who were 'highly knowledgeable and professional (S7)', 'helpful and approachable (S5)' ' flexible' and '[willing] to answer my many questions (S7).'

Challenging aspects included the Clients - particularly responding to their emotional state and developing therapeutic relationships, for example, 'challenging to see some men upset at coming in for the first time, so I found it hard to know what to say to them (S4).' Concerns raised about the Environment were that it was 'not a very busy environment to learn (S3)' 'it was difficult to navigate and find items necessary for procedures (S13),' 'the way they perform tasks differs to that of an acute care facility due to the minimal supply of products (S13),' time restrictions to care, and safety concerns, and 'having to wear a pass around my neck...this is a choking hazard and an easy target for an angry prisoner (S17).'

Staff Attitudes and Behaviours that students found challenging included the 'slightly "rough" seeming attitude of a few nurses...felt a little challenging to know how to interact with it (S8)', overt conflict between staff, 'the amount of swearing words the majority of the nurses use...not very professional (S10),' and inconsistency between staff, for example, 'getting told by different staff different things about what was and wasn't necessary to include in the reception interview paperwork (S8).' Students also commented on feeling Unprepared for the Placement, for example, 'perhaps the uni can have a discussion with students before saying, “It's not going to be how you think it is. It's serious. You're going into this environment and it's going to be shocking, it's going to be confronting” (S20)' and, 'I walked in the centre not knowing what was happening and felt quite overwhelmed but through observing and asking questions, I gradually understood it (S5).’ 
It commonly took students some time to integrate, with several stating that they did not cope until shortly before the placement ended. Students commented on appropriate student selection: 'Anyone that does go should have a real interest in wanting to work in there as some of the things seen are not for everyone....some...found it hard to separate the prisoner from their crime, therefore finding it difficult to treat them (S19)' and 'Just from speaking with other students... some students go into it thinking they're going to be seen as cool because they've done a prison placement (S20).'

\section{Preceptor effectiveness}

Seventy-eight percent of students worked with one to four preceptors, while $22 \%$ worked with five. Students were generally positive about their preceptors' qualities and behaviours (mean $4.17 \pm 1.20$ ) (Table 5) and teaching strategies (mean $4.16 \pm 1.17$ ) (Table 6). Fifteen (83.33\%) rated their preceptor/s' as good or outstanding (Figure 2).

Table 5. Students' perceptions of the qualities and behaviours of their preceptor/s.

\begin{tabular}{llll}
\hline Item & $\begin{array}{l}\text { Disagree/ } \\
\text { Strongly } \\
\text { Disagree (n) }\end{array}$ & $\begin{array}{l}\text { Agree/ } \\
\text { Strongly } \\
\text { Agree (n) }\end{array}$ & Mean \\
\hline Up-to-date knowledge and practice & $11.1 \%(2)$ & $88.23 \%(15)$ & $4.28( \pm 1.18)$ \\
Willingness to provide feedback & $11.1 \%(2)$ & $77.78 \%(14)$ & $4.17( \pm 1.20)$ \\
$\begin{array}{l}\text { Flexibility in facilitating my } \\
\text { learning experience }\end{array}$ & $11.1 \%(2)$ & $88.23 \%(15)$ & $4.22( \pm 1.17)$ \\
\hline
\end{tabular}




\begin{tabular}{lccc} 
Professionalism & $16.67 \%(3)$ & $88.89 \%(16)$ & $4.17( \pm 1.25)$ \\
$\begin{array}{l}\text { Supported my learning experience } \\
\text { Effective management of group }\end{array}$ & $16.67 \%(3)$ & $88.23 \%(15)$ & $4.22( \pm 1.26)$ \\
$\begin{array}{l}\text { dynamics } \\
\text { Effective utilisation of debriefing } \\
\text { sessions }\end{array}$ & $16.67 \%(3)$ & $77.78 \%(14)$ & $4.06( \pm 1.26)$ \\
& & $88.23 \%(15)$ & $4.11( \pm 1.23)$ \\
Mean ( \pm S.D.) & & & $4.17( \pm 1.20)$ \\
\hline
\end{tabular}

Table 6. Students’ perceptions of their preceptor's teaching strategies.

\begin{tabular}{lllll}
\hline Item & $\begin{array}{l}\text { Disagree / } \\
\text { Strongly } \\
\text { Disagree (n) }\end{array}$ & $\begin{array}{l}\text { Agree / } \\
\text { Strongly } \\
\text { Agree (n) }\end{array}$ & Mean \\
\hline $\begin{array}{l}\text { Encouraged me to contribute to the } \\
\text { clinical assessment process }\end{array}$ & $16.67 \%$ (3) & 88.33\% (15) & $4.22( \pm 1.26)$ \\
$\begin{array}{l}\text { Successfully oriented me to the health } \\
\text { facility/service, staff and emergency } \\
\text { procedures }\end{array}$ & $11.1 \%(2)$ & $88.89 \%(16)$ & $4.22( \pm 1.11)$ \\
$\begin{array}{l}\text { Assisted me to develop effective } \\
\text { communication strategies in the clinical } \\
\text { environment }\end{array}$ & $16.67 \%(3)$ & $88.23 \%(15)$ & $4.11( \pm 1.23)$ \\
& & & \\
\hline $\begin{array}{l}\text { Encouraged active learning using critical } \\
\text { thinking }\end{array}$ & $11.1 \%(2)$ & $88.33 \%(15)$ & $4.17( \pm 1.15)$ \\
\hline
\end{tabular}


Offered individual help and supervision with clinical procedures

$11.1 \%(2) \quad 77.78 \%(14) \quad 4.11( \pm 1.18)$

Promoted the integration of on and off campus learning in relation to key learning concepts and new learning $16.67 \%(3) \quad 77.78 \%(14) \quad 4.00( \pm 1.24)$ material

Helped me achieve my learning objectives

$16.67 \%(3) \quad 88.23 \%(15) \quad 4.11( \pm 1.37)$

Gave me constructive feedback on my performance

$11.1 \%(2) \quad 88.89 \%(16) \quad 4.33( \pm 1.34)$

Mean ( \pm S.D.)

$4.16( \pm 1.17)$

\section{Percentage}

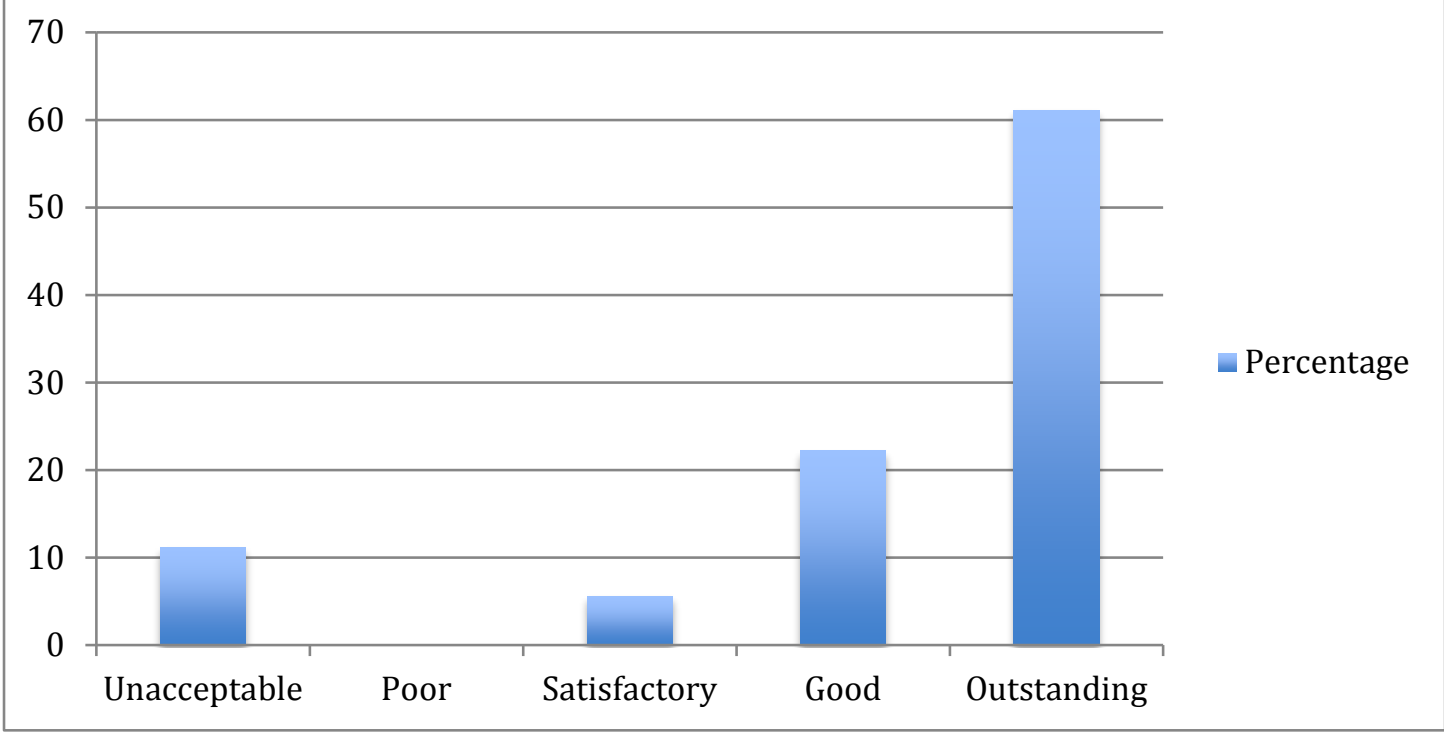

Figure 2. Students' overall perceptions of preceptor(s)' effectiveness (\%). 
Most students indicated their preceptors had outstanding qualities, 'she was by far the best buddy nurse I've had through my entire degree (S8).’ Preceptors were largely considered highly knowledgeable and excellent professional role models. Students felt enabled to follow their example when unsure how to interact with prisoners, for example, '[It was]...challenging to see some men upset at coming in for the first time, so I found it hard to know what to say to them but my buddies were great with this, so I was able to follow their examples (S4).'

Behaviours and Practices that Supported Learning included 'being supportive in a challenging environment (S5),' 'encouraging me (S17),' 'always willing to provide me with feedback in a positive way (S15),' '[allowing] me to make decisions independently and perform tasks under supervision (S13)', '[encouraging] me to be confident in my practice which enabled me to use my critical thinking skills when nursing clients (S13),' [trusting] my skills, which was great for my confidence (S4)', and '[treating] me like a co-worker, as opposed to a student on placement, which supported my learning experience (S13).'

Preceptor Qualities that Supported Learning included 'such a knowledgeable nurse; she assisted me with my professional development and provided me with amazing mentoring that will help me become a better practitioner (S15),' 'empathy for the offenders (S7),' 'clearly enjoyed working with students...had a positive attitude which really brightens your work day (S8),' 'very professional with clients and other staff... took great care and pride in her work...highly systematic and organised approach (S8),' and 'fun to work with (S15).' Some preceptors were considered well-meaning but not good teachers. Themes on perceived areas of difficulty included:

- Lack of Continuity, 'I had a different RN almost everyday' (S10) 
- Lack of Preceptor Engagement:

o Other priorities, 'my other two preceptors were more concerned with fulfilling their daily tasks ... I found myself following and observing rather than performing hands on... this experience would have been more educational if they allowed me to practice as a third year nursing student under their supervision' (S13)

o Not wanting students, 'you just work around those nurses who do not want to know about you' (S19)

o Attitudes, 'I thoroughly enjoyed [the placement], but there are tough people in there to work with and that's not just the prisoners' (S19).

\section{DISCUSSION}

This cohort of nursing students largely spoke highly of their placement and preceptors, which reflects the experience of other student health professionals placed in correctional settings (Leamon, Fields, Cox, Scott, and Mirassou, 2001; Sufrin, Autry, Harris, Goldenson, \& Steinauer, 2012). Students mostly felt they had met the course learning objectives. Similar themes have been found when evaluating the outcomes of nursing and other student health professionals undergoing prison health placements. For example, second year nursing students in Florida were thought to have developed enhanced clinical skills with a focus on health maintenance and prevention of illness (Chapell \& Chase, 1986). Additionally Canadian undergraduate medical students (Filek et al., 2013) were found to benefit from prison placements through enhanced relationship building, breaking down of barriers and stigma through interaction with prisoners, development of insight into issues faced by marginalised populations, and development of collaborative teamwork skills. Similarly, 
medical residents who rotated through the San Francisco County Jail, viewed their placement as a positive experience, where they met learning objectives, developed counselling skills and gained insights into the social determinants of health (Sufrin et al., 2012).

Our students felt the learning outcomes for the clinical placement needed to be made more explicit. Haley, Ferguson, Brewer, and Hale (2009) conducted focus groups with health professionals to investigate the elements required for a prison healthcare curriculum. They found that healthcare providers in prisons require knowledge of common personal characteristics of prisoners, prevalent health conditions, public health opportunities, ethics and medico-legal issues, and system and structural issues. After their rotation, students in one program requested a more structured curriculum, citing a lack of organised schedule, and time spent watching rather than performing clinical tasks (Alemagno et al., 2004). This is congruent with some of the feedback from our participants indicating that more attention needs to be paid to this aspect of the placement.

Students commented on the time required to feel comfortable in this environment and requested a more detailed orientation to better support their integration. The literature also supports the need for psychological preparation including exploration of feelings, expectations of the experience, and awareness of stereotypes (Boyd \& Mott, 1999; Kovalesky, 2005). Orientation programs also need to address unique aspects of the prison health setting, including security and safety issues, institutional rules and routines, as well as legal and ethical aspects related to confidentiality and prisoner rights (Alemagno et al., 2004; Felton et al., 1987; Fontes, 1991). Other important aspects of orientation should include interactions with prisoners - including gifts, granting requests, personal disclosure, eye contact, and maintaining professional boundaries (Boyd \& Mott, 1999). 
Simulation may offer a means of introducing students to the prison setting, developing critical thinking about complex patients and situations, and thus reducing anxiety, improving proficiency, safety and security, and enhancing communication (Diaz, Panosky, \& Shelton, 2014). Other benefits of simulation can include the discovery of diverse learning practices, improved teamwork, and inter- and intra-professional role recognition and differentiation.

Students identified a range of helpful characteristics exhibited by their preceptors during their clinical experience including: being supportive, encouraging, providing positive feedback, allowing autonomous practice, being knowledgeable, empathetic, exhibiting a positive attitude, being a good role model and making learning fun. Most students’ considered their preceptors behaved professionally and their preceptors' current knowledge and practice, flexibility, support and effective debriefing skills were also acknowledged. However, willingness to provide feedback and effective management of group dynamics was rated lowest. Charleston and Happell (2005) found that general nursing students in a psychiatric setting desired assistance from their preceptors to cope with uncertainty. They appreciated regular feedback, and those with positive support were more relaxed and able to learn. This suggests that preceptors need educational support to provide student feedback and supported practice opportunities to improve their management of group dynamics.

\section{$\underline{\text { Study limitations }}$}

This was a small study conducted with one cohort of nursing students in four Australian metropolitan prisons. The small sample did not allow inferences to be made related to variables such as age and gender of the participants. Therefore the results cannot be generalised to other prisons and other cohorts of nursing students. 


\section{CONCLUSIONS}

Prison health settings provide nursing students with a valid alternative placement to enable them to achieve their learning objectives. Student outcomes may improve if they are prepared for the challenging behaviours inherent within the prison environment. Therefore, a specific orientation program may help to maximise the benefits of this non-traditional placement, by improving the integration of students into the unfamiliar environment, and providing them with strategies to understand and communicate with both staff and prisoners. These innovative placements have increased the available placements for third year students and provided the opportunity for them to integrate primary health care in the prison health arena.

\section{Conflicts of interest: none.}

\section{REFERENCES}

Alemagno, S. A., Wilkinson, M., \& Levy, L. (2004). Medical education goes to prison: why? Acad Med, 79(2), 123-127.

Almost, J., Gifford, W. A., Doran, D., Ogilvie, L., Miller, C., Rose, D. N., \& Squires, M. (2013). Correctional nursing: a study protocol to develop an educational intervention to optimize nursing practice in a unique context. Implement Sci, 8, 71.

Australian Bureau of Statistics. (2015b). Prisoners in Australia 2015. Retrieved from Canberra: http://www.abs.gov.au/ausstats/abs@.nsf/mf/4517.0

Australian Institute of Health and Welfare. (2015a). The health of Australia's prisoners 2015. Retrieved from http://www.aihw.gov.au/WorkArea/DownloadAsset.aspx?id=60129553682 
Australian Institute of Health and Welfare. (2015b). National health priority areas. Retrieved from http://www.aihw.gov.au/national-health-priority-areas/

Bennett, C., Perry, J., Lapworth, T., Davies, J., \& Preece, V. (2010). Supporting prison nurses: an action research approach to education. British J Nurs, 19(12): 782-786.

Boyd, S. M., \& Mott, D. (1999). Taking students to prison. J Nurs Educ, 38(5), 235-237.

Chapell, V. R., \& Chase, B. M. (1986). The expanded community role: "jail" experience. J Nurs Educ, 25(3), 120-121.

Charleston, R., \& Happell, B. (2005b). Psychiatric nurses and undergraduate nursing students' perceptions of preceptorship in the mental health setting. Int J Psychiatr Nurs Res, 10(3), 1166-1178.

Cohen, B. E., \& Gregory, D. (2009). Community health clinical education in Canada: part 2 developing competencies to address social justice, equity, and the social determinants of health. International Journal of Nursing Education Scholarship, 6(1), 1p.

Diaz, D. A., Panosky, D. M., \& Shelton, D. (2014). Simulation: Introduction to Correctional Nursing in a Prison Setting. J Correct Health Care, 20(3), 240-248.

Durcan, G. (2006). Equivalent to what? Mental health care in Britain's prisons. The Journal of Mental Health Workforce Development, 1(4), 36-48.

Enggist, S., Møller, L., Galea, G., \& Udesen, C. (Eds.). (2014). Prisons and Health. Copenhagen, Denmark: World Health Organization Regional Office for Europe. Retrieved from http://www.euro.who.int/_ data/assets/pdf_file/0005/249188/Prisonsand-Health.pdf

Faculty of Health Social Care \& Education. (2015). Overview of adult nursing placements Across Essex, Cambridgeshire, Hertfordshire and London: Anglia Ruskin University. Felton, G., Parsons, M. A., \& Satterfield, P. (1987). Correctional facilities: a viable community health practice site for students. J Community Health Nurs, 4(2), 111-115. 
Filek, H., Harris, J., Koehn, J., Oliffe, J., Buxton, J., \& Martin, R. (2013). Students' experience of prison health education during medical school. Med Teach, 35(11), 938-943.

Fontes, H. C. (1991). Prisons. Logical, innovative clinical nursing laboratories. Nurs Health Care, 12(6), 300-303.

Forensicare. (2015). Undergraduate Nursing Program. Retrieved from http://www.forensicare.vic.gov.au/page.aspx?o=unp

Georges, C. A. (1986). A prison health setting as a clinical laboratory for undergraduate nursing students. J Natl Black Nurses Assoc, 1(1), 36-40.

Haley, H.-L., Ferguson, W., Brewer, A., \& Fraser Hale, J. (2009). Correctional Health Curriculum Enhancement Through Focus Groups. Teach Learn Med, 21(4), 310-317.

Juanitez, J. B. T. (2015). Exploring Life Behind Bars: Student Nurses' Visit to New Bilibid Prison. Retrieved from http://www.olivarezcollege.edu.ph/exploring-life-behindbars-student-nurses-visit-to-new-bilibid-prison/

Justice Health and Forensic Mental Health Network. (2015). Student Clinical Placements. Retrieved from http://journals.rcni.com/doi/pdfplus/10.7748/ns.29.37.66.s51

Kaufman, A., Holbrook, J., Collier, I., Farabaugh, L., Jackson, R., \& Johnston, T. (1979). Prison health and medical education. Journal of Medical Education, 54(12), 925-931. Kovalesky, A. (2005). Correctional Facilities as Community Health Clinical Placement Sites for RN to BSN Students. Journal of Correctional Health Care, 11(2), 125-135.

Leamon, M. H., Fields, L., Cox, P. D., Scott, C., \& Mirassou, M. (2001). Medical students in jail: The psychiatric clerkship in an outpatient correctional setting. Academic Psychiatry, 25(3), 167.

Martin, T., \& Happell, B. (2001). Undergraduate nursing students' views of mental health nursing in the forensic environment. Aust N Z J Ment Health Nurs, 10(2), 116-125. 
Norman, A. (1999). Nursing students should go to jail. Nurs Stand, 14(10), 58.

Peternelj-Taylor, C. A., \& Johnson, R. (1996). Custody and caring: clinical placement of student nurses in a forensic setting. Perspect Psychiatr Care, 32(4), 23-29.

Queensland Corrective Services. (2006). Offenders with specific needs Policy and Action Plan 2006 - 2009. Retrieved from http://www.correctiveservices.qld.gov.au/Publications/Corporate_Publications/Strateg ic_Documents/Specific_Needs_Action_Plan.pdf

Stewart, W. (2007). Exploring learning opportunities for nursing students in prison settings. Nurs Stand, 22(2), 40-41.

Sufrin, C. B., Autry, A. M., Harris, K. L., Goldenson, J., \& Steinauer, J. E. (2012). County jail as a novel site for obstetrics and gynecology resident education. $J$ Grad Med Educ, 4(3), 346-350.

Tewa, S. (2014). A Legacy of Caring, Innovation, and Pride: Lehman’s Department of Nursing Marks 40 Years. Retrieved from http://wp.lehman.edu/lehmantoday/2014/01/a-legacy-of-caring-innovation-and-pride-lehmans-department-ofnursing-marks-40-years/

Thomas, E., Spittal, M., Taxman, F., \& Kinner, S. (2015). Health-related factors predict return to custody in a large cohort of ex-prisoners: new approaches to predicting reincarceration. Health \& Justice, 3(1), 1-13.

Warrilow, A. (2012). Improving the mental health care of prisoners: nurses face many barriers when providing a service for detainees equivalent to that offered in the community. Mental Health Practice, 15, 20. 